\title{
Achievement Test of Education Students in Assessment of Student Learning
}

\author{
Mark Angelo C. Reotutar ${ }^{1}$, Norie T. Tactay ${ }^{2}$, Muhammad Ridwan \\ ${ }^{1,2}$ University of Northern Philippines, Philippines \\ ${ }^{3}$ Universitas Islam Negeri Sumatera Utara, Indonesia \\ mark.angelo_reotutar@yahoo.com,norie.tactay@unp.edu.ph,bukharyahmedal@gmail.com
}

\begin{abstract}
The study attempted to determine the level of achievement of the selected education students in Assessment of Student Learning. It was also tested if there existed a significant differences between and among the achievement of the four groups of respondents. The samples of the study were education students enrolled in Assessment of Student Learning. The first group of respondents were the Bachelor of Secondary Education (BSEd) students. The second group were the Bachelor in Elementary Education (BEED) group. The third were the students enrolled in Bachelor in Industrial Education (BSIE) students. A 25-item test which was adopted from assessment books was used check the level of achievement of the respondents. Mean, Standard Deviation, ANOVA, and Sheffe's Test were used as a statistical tools to treat and analyze the data gathered. The Bachelor in Industrial Education and Bachelor of Elementary Education groups performed very good while the Bachelor of Secondary Education and Bachelor in Library and Information Science groups were at good level. The overall performance of the four groups of respondents were very good. There exist significant differences between and among the means of the achievement of the respondents. Based from the findings of the study, the researcher concluded that the level of achievement of the respondents in Assessment of Student Learning was very good. In addition, there existed significant differences between and among the achievement of the four group of respondents. The study recommends that students enrolled in assessment should be encourage to be outstanding in their performance and a further study using other respondents be conducted to validate the results.
\end{abstract}

Keywords

development; local assessment of learning; level of achievement; difference on the level of achievement; education students

\section{Introduction}

Education plays an important role to every individual because it equips him/her with the necessary knowledge and skills needed to become a functional member of the society. Reotutar, M.A. (2020) defined education to be very important to humans especially the children since it helps them attain their dreams in life. According to the World Bank, education can also be one of the strongest instruments for reducing poverty, thereupon improving the well-being of the people. However, to establish and maintain a high-quality education system, proper investments must be made (Philippine Institute for Developmental Studies, 2012). More so, there is a need to highlight the competence of students specifically the education students in subjects that prepares them for their future career, including one of their professional subjects such as the Assessment of Student Learning. 
Assessment of Learning is offered to all students taking up education courses. It is where they will experience how to construct assessment instrument considering validation and reliability test. In addition, they will also experience how to do a test administration and evaluation. Creating a test instrument is very critical or crucial. It is because you must know the steps, rules and proper ways in test construction. Teachers need to review the important principles underlying assessment. They need to impart in their mind about why they are giving such to their students. They should be aware about the real benefits of assessing their students' achievement.

According to Sitorous, M.N., Yus, A. \& Saragi, D. (2020), assessment is very important for teachers since it may also increase the quality of instruction inside the classroom. It may serve as a stepping-stone to comply with the institutions' administrative rules and policies. The authors also emphasized in their study that assessment can see the extent of achievement of learners with respect to their set learning goals and outcomes. However, there are also instances that nonexistence of students' attentiveness in learning fallouts to pre-determined wisdom goals not being realized (Gultom, S., Hutauruk, A.F., \& Ginting, A.M. 2020).

Assessment is a complex subject. It compose of so many important concepts that education students should know. One important note in dealing with assessment of learning is the alignment of instruction and assessment. If the instruction does not properly aligned with the assessment, then it follows that the assessment instrument with be invalid. Moreover, before doing an assessment you should for do a review on the set objectives because it's nonsense to give assessment without referring to the objectives. As Capate, et al. (2015) stated, whatever objective is stated, it should be realized during instruction. Consequently, the assessment method should be according to how the subject is taught and should be according to the stated objectives.

You give test for instruction, this is what diagnostic assessment tells us. You give test to check the progress of the learners, this is what formative assessment tells. And you give test to determine the mastery level, this is summative assessment.

As the world becomes complex, the skills that students need to acquire and master are quickly changing. The rise of global economy, an increasing multicultural society, and rapid changes in technology require students to learn and apply new skills in their academic and career endeavors. Students need to learn to communicate more effectively, both through speech and the written word. They need to learn how to work with others to find new and better ways to solve problems and meet the challenges of everyday life. They need to develop skills they can use in college or the workforce.

Perhaps most important, students need to discover the joy of learning. If students are to function effectively in this ever-changing world, they must continue to learn everyday of their lives.

This study was focused on determining the level of achievement of the education students enrolled in Assessment of Student Learning during the first semester of the academic year 2015-2016.

\subsection{Statement of the Problems}

This study sought to answer the following questions:

1. What is the level of achievement of the four groups of respondents enrolled in Assessment of Student Learning?

2. Is there a significant difference between and among the level of achievement of the four groups of respondents in Assessment of Student Learning? 


\subsection{Hypothesis of the Study}

The hypothesis stating that there is no significant difference between and among the level of achievement of the four groups of respondents in Assessment of Student Learning was tested at 0.05 probability level of significance.

\section{Review of Literatures}

The following related studies were presented to give support on the data gathered for this study.

Student achievement has become a hot topic in education today, especially with increased accountability for classroom teachers. The ultimate goal for any teacher is to improve the ability level and prepare students for adulthood. Defining students' achievement and factors that impact progress is critical to becoming a successful teacher. Student achievement measures the amount of academic content a student learns in a determined amount of time. Each grade level has learning goals or instructional standards that educators are required to teach. Standards are similar to a 'to-do' list that a teacher can use to guide instruction. Student achievement will increase when quality instruction is used to teach instructional standards. (https://en.m.wikipedia.org/wiki/Academic_achievement).

Crooks (1988) summarizes results from 14 specific fields of research that cast light on the relationship between classroom evaluation practices and student outcomes. Particular attention is given to outcomes involving learning strategies, motivation and achievement. Where possible, mechanisms are suggested that could account for the reported effects. The conclusions derived from the individual fields are then merged to produce an integrated summary with clear implications for effective educational practices. The primary conclusions is that classroom evaluation has powerful direct and indirect impacts, which may be positive or negative. And thus deserves very thoughtful planning and implementation.

According to Navarro, et al (2013), the terms assessment, evaluation, testing and marks are terms often used in determining degree of attainment of student learning outcomes. At times they are used interchangeably, it will be useful to clarify their meanings to distinguish them from one another.

Assessment refers to the process of gathering data and information about what students know and can do. Such information may be sourced through observation of students during their learning activities, examining the results of their learning activities or testing their knowledge and skills. Through assessment, the teacher can find out what students are learning.

Evaluation involves the task of interpreting, forming conclusions and making judgments about the information which was gathered in the process of assessment. The data gathered by assessment are neither useful nor useless but they reflect the learning process. Such information becomes meaningful only when they are processed and interpreted as to how well the students are attaining their desired competencies.

Testing is an instrument of assessment. A test is an assessment tool that reflects the records of the students' learning outcomes. Marks are reports of the results of evaluating information obtained in the assessment process. Marks have certain components related to the learning activities undertaken by the students. Moreover, Assessment involves review of evidence of learning such as journal entries, written work, portfolios, skills demonstrations, performance in learning activities, test results and rubrics rating which cover a period time and should reveal the progress of students in competencies. Evaluation on the other hand occurs when a mark or grade is assigned after a quiz, a presentation or a completed task. 
In the study conducted by Zeidner (2015) entitled "Essay vs Multiple-Choice Type Classroom Exams: The Student's Perspective" compared students' attitudes and dispositions toward teacher-made essay vs multiple-choice type exams. He administered two modes of test attitude inventory to assess students' attitudes towards essay and multiple-choice type formats on a variety of critical formats. Overall, the data from the two modes of test attitude inventory were both remarkably consistent, pointing to more favorable student attitudes towards multiple choice compared to essay type formats on most dimensions assed. The practical significance of the results for classroom test construction are discussed and some suggestions are made about potential future applications of test attitude inventories in the classroom setting.

Palmer, E. et al. (2007) conducted an analysis on multiple-choice questions (MCQs) and modified essay questions (MEQs) used for summative assessment in clinical undergraduate curriculum. Their study was design to assess the effectiveness of the MEQs to measure higher-order cognitive skills in an undergraduate institution. Over $50 \%$ of all the MEQs tested factual recall. This was similar to the percentage of MCQs testing factual recall. The modified essay question failed in its role of consistency assessing higher cognitive skills whereas the MCQ frequently tested more than mere recall of knowledge. They concluded that construction of MEQs which will assess higher order cognitive skills cannot be assumed to be a simple task. Well-constructed MCQs should be considered a satisfactory replacement for MEQs if the MEQs cannot be designed to adequately test higher order skills. Such MCQs are capable of withstanding the intellectual and statistical scrutiny imposed by a high stakes exit examination.

Based from the related literatures presented, the similarities of the researches to the present research is they both deal with testing and assessing students. On one side, the present study only focused on determining the performance of the education students in their assessment subject using a pure multiple choice questions.

\subsection{Conceptual Framework}

The paradigm below shows the simplified focus of this study.

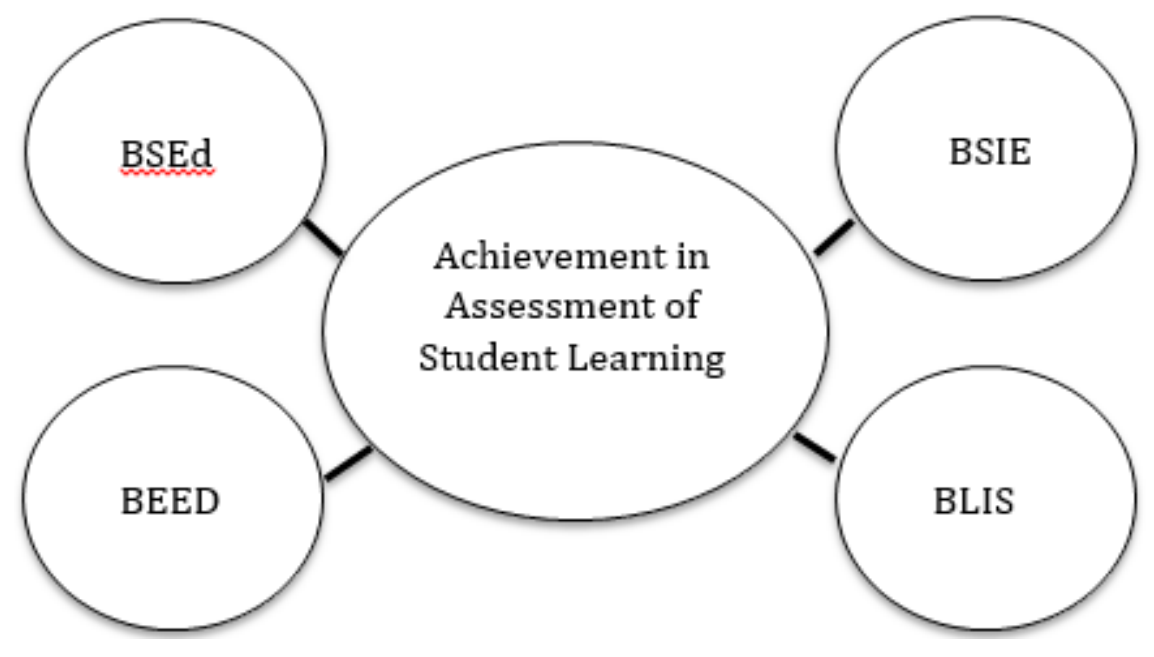

Figure 1. Conceptual Paradigm

Figure 1 shows the level of achievement of the four groups of respondents in Assessment of Student Learning. It also shows the interaction of the four groups of respondents showing the differences between and among their achievement. 


\subsection{Operational Definition of Terms}

The following terms are defined herein:

Students' Achievement, it refers to the overall performance and amount of academic content learned by the students in the subject Assessment of Student Learning. Assessment of Student Learning. It is a subject offered in the College of Teacher Education divided into two courses which serve as one of the professional subjects of education students.

\section{IIII. Research Method}

The researcher use a descriptive research design to determine the level of achievement of the respondents in Assessment of Student Learning. This design is appropriate since this study deals with recording and tabulating data to come up with factual results.

\subsection{Population of the Study}

Table 1. Distribution of the Respondents in the Four Programs of the College of Teacher Education

\begin{tabular}{|c|c|c|}
\hline Programs & $\mathbf{N}$ & $\%$ \\
\hline Bachelor of Secondary Education & 57 & 34.34 \\
\hline Bachelor of Elementary Education & 48 & 28.92 \\
\hline Bachelor in Industrial Education & 45 & 27.11 \\
\hline Bachelor in Library and Information Technology & 16 & 9.64 \\
\hline Total & 166 & $\mathbf{1 0 0 . 0 0}$ \\
\hline
\end{tabular}

Table 1 shows that there were 166 students who served as respondents of the study. This group was categorized according to the four programs offered by the College of Teacher Education in University of Northern Philippines during the Academic Year 20152016. Fifty-seven of which were students of the Bachelor of Secondary Education (BSEd) program. There where forty-eight who belongs to the Bachelor of Elementary Education (BEED) program. Forty-five students belong to the Bachelor in Industrial Technology (BSIE) and sixteen in the Bachelor of Library and Information Services (BLIS) program. The BSEd, BEED and BSIE groups completed the two courses in Assessment of Student Learning while the BLIS only have knowledge on the first course.

\subsection{Data Gathering Instrument}

The instruments used in the study were the 25-item multiple choice adopted from the Assessment book. The researchers used the following norms as basis in determining the achievement of the four groups of respondents:

\section{Descriptive Rating(DR)}

Outstanding $(\mathrm{O})$

Very Good(VG)

$\operatorname{Good}(\mathrm{G})$

Poor(P)

Needs Improvement(NI)

\section{Range of Scores}

$$
\begin{gathered}
20.01-25.00 \\
15.01-20.00 \\
10.01-15.00 \\
5.01-10.00 \\
0.00-5.00
\end{gathered}
$$




\subsection{Data Gathering Procedures}

The researchers wanted to determine the level of achievement of the students of the College of Teacher Education enrolled in Assessment of Student Learning. The researchers administered the adopted questionnaire to the respondents, checked, analyzed and interpreted through the use of statistical tools.

\subsection{Statistical Treatment of Data}

The following statistical tools were used to analyze and interpret the data gathered:

- Mean $(\bar{x})$ was used to determine the level of achievement of the respondents in Assessment of Student of Learning.

- Standard Deviation (s) was used to determine the average distances of the scores of the respondents around the mean.

- Analysis of Variance (ANOVA) was used to determine the significant difference between and among the level of achievement of the respondents in Assessment of Student Learning.

- Scheffe's Test was also used to determine further the group who causes the significant differences.

\section{Discussion}

This part of the research discusses the result of the research conducted.

4.1 Level of achievement of the students after taking the achievement test in Assessment of Student Learning.

Table 2 shows the mean performance of the four groups of respondents in Assessment of Student Learning.

Table 2. Level of Achievement of the Respondents in Assessment of Student Learning

\begin{tabular}{|l|c|c|c|}
\hline Respondents & $\overline{\mathbf{x}}$ & $\mathbf{D R}$ & $\mathbf{S}$ \\
\hline BSEd & 12.33 & Good & 2.093 \\
\hline BEED & 12.63 & Very Good & 1.996 \\
\hline BSIE & 15.13 & Very Good & 1.922 \\
\hline BLIS & 12.00 & Good & 1.966 \\
\hline Overall mean & $\mathbf{1 3 . 2 5}$ & Very Good & $\mathbf{1 . 9 6 1}$ \\
\hline
\end{tabular}

It can be observed from the table that the level of achievement of the BEED and BSIE students were Very Good since their mean rating were 12.63 and 15.13 , respectively. On the other hand, the BSEd and BLIS group were at Good Level $(\bar{x}=12.33$ and 12.00$)$, respectively.

On the other hand, the standard deviations tells the average distances of the scores of the four groups of respondents around their means. It shows that the BSIE group has the least value of standard deviation (1.92). This would imply that the scores of the BSIE group were more intact to their mean of 15.13 as compared to the other group of respondents. It further imply that the BSIE group were considered to be homogeneous in terms of their performance in the examination. 
4.2 Is There a Significant Difference between the Levels of Achievement of the Students?

Table 3 presents the significant difference between and among the levels of achievement of the students in Assessment of Student Learning.

Table 3. ANOVA Results of the Significant Difference on the Level of Achievement of the Four Groups of Respondents

\begin{tabular}{|l|c|c|c|c|c|c|}
\hline $\begin{array}{c}\text { Sources of } \\
\text { Variation }\end{array}$ & $\begin{array}{c}\text { Degrees } \\
\text { of } \\
\text { freedom }\end{array}$ & $\begin{array}{c}\text { Sum of } \\
\text { Squares }\end{array}$ & $\begin{array}{c}\text { Mean } \\
\text { Square }\end{array}$ & $\begin{array}{c}\text { F - } \\
\text { value }\end{array}$ & $\begin{array}{c}\text { p- } \\
\text { value }\end{array}$ & Interpretation \\
\hline Between Groups & 3 & 93.183 & 31.061 & 7.805 & 0.000 & Significant \\
\cline { 1 - 4 } Within Groups & 58 & 230.817 & 3.980 & & & \\
\hline Total & 61 & 324.00 & & & & \\
\hline
\end{tabular}

Table 3 revealed that there existed a significant difference between and among the level of achievement of the four groups of respondents using the One-way Analysis of Variance (ANOVA) as statistical tool as manifested from the computed p-value of 0.000 . This means that the means scores of the four groups were unlike. To determine which among the group shows a significant difference/s the Scheffe's test was used.

It can be seen from the Table 4 that there existed significant differences between BSEd and BEED group; BEED and BSIE group; and BEED and BLIS group as manifested by their mean differences respectively.

Table 4. Multiple Comparison of the Significant Difference on the Level of Performance of the Control Group and the Experimental Group

\begin{tabular}{|c|c|c|c|}
\hline Comparison & Mean Difference & Std. Error & Sig. \\
\hline BSEd vs BEED & -.29167 & .71696 & .983 \\
\hline BSEd vs BSIE & $-2.80000^{*}$ & .72843 & .004 \\
\hline BSEd vs BLIS & .33333 & .71696 & .975 \\
\hline BEED vs BSIE & $-2.50833^{*}$ & .71696 & .011 \\
\hline BSIE vs BLIS & .62500 & .70530 & .853 \\
\hline BEED vs BLIS & $3.13333^{*}$ & .71696 & .001 \\
\hline
\end{tabular}

* significant at .05 level

\section{Conclusions}

Based on the findings, the following conclusions are drawn:

1. The level of achievement of the respondents in Assessment of Student Learning was very good. Hence, the BLIS group were found to be the lowest achievement.

2. There existed significant differences between and among the levels of achievement of the four group of respondents.

\section{Recommendations}

From the conclusions drawn, the following recommendations are advanced:

1. Students who will be taking up Assessment of Student Learning should be encouraged to achieve an outstanding performance rather than very good or good performance only. 
2. The Administrator should engage the BLIS group to take Assessment of Student Learning 2 for them to complete the totality of the subject.

3. Further study will be conducted using different respondents for the validation of the results. Inclusion of interview to the respondents should also be done to verify the result of the test.

\section{References}

Navarro, R. et al. (2013). Authentic Assessment of Student Learning Outcomes, Lorimar Publishing Inc.

Capate, et al. (2015). Assessing the Mathematics Performance of Grade 8 Students as Basis for Enhancing Instruction and Aligning with $k$ to 12 Curriculum, De La Salle University Philippines.

Claudia, F. Houston Texas. Student achievement: Definition, factors \& research. Study.com. Retrieved from https//study.com/academy/lesson/student-achievementdefinition-factors-research.html

Crooks, T. (1988). The Impact of Classroom Evaluation Practices on Students, SAGE Journal.

Gultom, S., Hutauruk, A.F., \& Ginting, A.M. (2020). Teaching Skills of Teacher in Increasing Student Learning Interest. Budapest International Research and Critics Institute-Journal (BIRCI-Journal). $\quad$ Retrieved from https://doi.org/10.33258/birci.v3i3.1086

Palmer, E. (2007). Assessment of Higher Order Cognitive Skills in Undergraduate Education: Modified Essay or Multiple-choice Questions, BMC Medical Education.

Reotutar, M.A. (2020). Teacher Education Freshmen Applicants' Current State in the New Normal Learning Delivery Platforms. BirLE-Journal: Budapest International Research and Critics in Linguistics and Education. Retrieved from https://doi.org/10.33258/birle.v3i3.1227

Sitorous, M.N., Yus, A. \& Saragi, D. (2020). Development of Computer-based Kindergarten Children's Creativity Portfolio Assessment Instruments. BirLEJournal: Budapest International Research and Critics in Linguistics and Education. Retrieved from https://doi.org/10.33258/birle.v3i3.1207

Zeidner, M. (1987). Essay versus Multiple-Choice Type Classroom Exams: The Students' Perspective. The Journal of Educational Research. 